\title{
Publisher Correction: Tax havens and global environmental degradation
}

Victor Galaz (1), Beatrice Crona, Alice Dauriach, Jean-Baptiste Jouffray (1D, Henrik Österblom (1) and Jan Fichtner (1)

Correction to: Nature Ecology \& Evolution https://doi.org/10.1038/s41559-018-0497-3 (2018), published online 13 August 2018.

An earlier version of the Supplementary Information was mistakenly uploaded when this Perspective was published, and was live until 14 August 2018, when the correct version was uploaded. 